\title{
Sublingual ectopic thyroid gland diagnosed with subclinical hypothyroidism in the pubertal period
}

\begin{abstract}
Ectopic thyroid is a rare entity and can ocur at any location in the midline position. Cases with this embryologic abnormality are usually diagnosed with mass and pressure symptoms in the second and third decades. A 13-year-old female patient was referred to our clinic with subclinical hypothyroidism. The patient did not describe any pressure symptoms and the physical examination did not reveal any mass in the neck region. An appearance consistent with ectopic thyroid gland was observed in the tongue root on thyroid ultrasonography. The patient was found to have a sublingual thyroid gland with thyroid scintigraphy. We present this case of sublingual thyroid gland with a clinical picture of subclinical hypothyroidism as it is rare.
\end{abstract}

Keywords: ectopic thyroid gland, subclinical hypothyroidism, pubertal period

\author{
Special Issue - 2018
}

\author{
Melikșah Keskin, Șenay Savaș Erdeve, Semra \\ Çetinkaya, Zehra Aycan \\ Pediatric Endocrinology Clinic, Dr. Sami Ulus Obstetrics and \\ Gynecology and Pediatrics Training and Research Hospital, \\ Turkey
}

Correspondence: Melikșah keskin, Pediatric Endocrinology Clinic, Dr. Sami Ulus Obstetrics and Gynecology and Pediatrics Training and Research Hospital,Turkey, Tel +9003 I 230565 I I, Email meliksah.keskin@hotmail.com

Received: May 16, 2017| Published: November 15, 2018

\section{Introduction}

Ectopic thyroid indicates a thyroid gland in a location other than the usual pretracheal site and is a rare embryological abnormality. ${ }^{1}$ The prevalence is 1 per 100,000 to 300,000 . It is seen in 1 per 4000 to 8000 thyroid disease patients. However, accurate figures are difficult to determine as asymptomatic cases can easily be overlooked. ${ }^{2} \mathrm{~A}$ lingual location is seen in $90 \%$ of ectopic cases and this location is also four times more common in females. ${ }^{1,3}$ The cases are usually diagnosed with symptoms of mass and pressure in the neck in the adolescent period and the third decade. ${ }^{2}$ Thyroid scanning with technetium$99 \mathrm{~m}$ is the best diagnostic method but other methods to determine the ectopic gland's location and extent include fine-needle aspiration cytology (can be difficult), ultrasonography, computed tomography and magnetic resonance imaging. ${ }^{4}$

Lingual thyroid usually causes symptoms such as dysphagia, choking, dyspnea, and hemorrhage but can even cause potentially fatal airway obstruction. Obstructive symptoms require shrinking the gland with Thyroxine replacement therapy at first, followed by surgery if this is unsuccessful. ${ }^{1}$ There have been rare reports of malignant conversion. Our objective in this study was to present a sublingual thyroid case that had caused subclinical hypothyroidism in the pubertal period and discuss the presentation, diagnosis and management of this rare case.

\section{Case presentation}

A 13-year-old female patient presented with symptoms of fatigue, weakness and tremor in the hands. She was referred to our clinic when the thyroid stimulating hormone (TSH) level was found to be elevated. The medical history revealed no other disorder. The parents had no kinship and there was no known significant disease in the family history. The physical examination at presentation revealed a patient in good general condition with a body temperature of $36.5^{\circ} \mathrm{C}$; apical heart beat 72 /minute, respiration rate 16 /minute and blood pressure 105/70 mmHg. Her height was $154.7 \mathrm{~cm}$ (SDS:-0.5) and weight 45.1 kg (SDS:-0.7). Breast development was consistent with Tanner stage 4 and pubic hair growth with Tanner stage 3 . There was no axillary hair. The thyroid gland could not be palpated bilaterally. Other system examination findings were normal. Laboratory tests revealed a TSH of $7.9 \mu \mathrm{IU} / \mathrm{ml}(0.6-5.5)$, free T4 $1.18 \mathrm{ng} / \mathrm{dl}(0.8-1.9)$, free T3 $4.61 \mathrm{pg} / \mathrm{ml}$ (2-6.5), anti-thyroidperoxidase (TPO)<28IU/mL $(0-60)$, anti-thyroglobulin $18.5(0-60) \mathrm{IU} / \mathrm{mL}$, urinary iodine $220 \mu \mathrm{g} / \mathrm{L}(100-$ 700 ), and thyroglobulin $61.9 \mathrm{ng} / \mathrm{mL}$. Thyroid gland ultrasonography of the patient revealed no soft tissue that could belong to thyroid parenchyma in the thyroid lodge. An area about $23 * 17 * 23 \mathrm{~mm}$ in size that could belong to ectopic thyroid parenchyma was noted at the level of the tongue root in the sub mental region. Confirmation with scintigraphy was recommended. Thyroid scintigraphy in the anterior position 20 minutes after Tc-99 m pertechnetate was administered intravenously showed activity consistent with a large focus of ectopic thyroid tissue at the sublingual region in the midline (Figure 1). There was no activity consistent with thyroid tissue in the thyroid lodge. The patient was started $25 \mathrm{mcg}$ Thyroxine therapy daily.

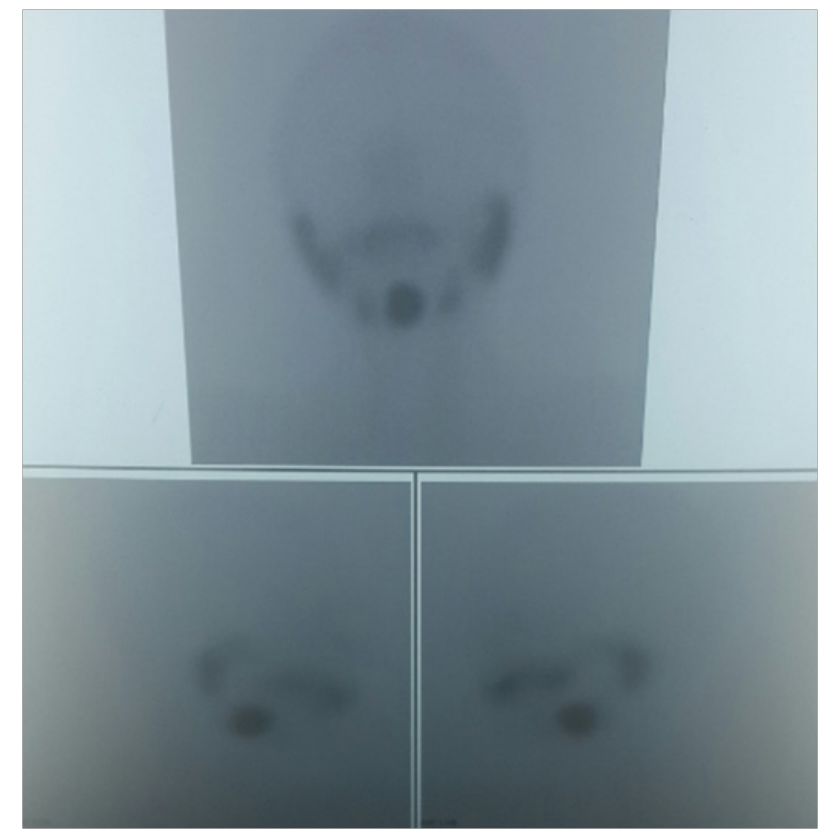

Figure I Image of the patient's thyroid scintigraphy. 


\section{Discussion}

The thyroid gland may stop at various locations along the thyroglossal duct during its descent from the lingual base and result in ectopic thyroid. Some of the common sites where ectopic thyroid tissue can be seen in the head and neck are the lingual base, submandibular or sublingual locations (between the geniohyoid and mylohyoid muscles), and prelaryngeal sites (anterior to the larynx and superior to the hyoid bone). Rare sites include the pharynx, esophagus, and the trachea while extra cervical sites include the pericardial sac and the heart, the mediastinum and the lungs, the breast, the duodenum, the small intestine mesentery, and the adrenal gland. ${ }^{4}$ The pathogenesis is generally unknown. It is reported that a mutation in the TTF-1, TTF-2 and PAX-8 transcription factors that are involved in thyroid morphogenesis and differentiation may result in abnormal thyroid bud migration. $^{2}$

The lingual region is the most frequent location for an ectopic thyroid and it accounts for approximately $90 \%$ of these cases. ${ }^{5}$ Lingual cases constituted $49 \%$ and sublingual cases $34.7 \%$ of all cases in a Korean study where 49 cases were evaluated retrospectively. A palpable mass was found in about $40 \%$ of the cases. ${ }^{2}$ Most ectopic thyroid cases have been reported to be asymptomatic and diagnosed incidentally in another study. ${ }^{6}$ Although the ectopic thyroid gland secretes thyroid hormone that shows normal chemical function, the secreted amount can be insufficient in conditions such as puberty, pregnancy, infection and trauma where the need for thyroid hormones increases. ${ }^{2}$ The increased TSH level in the circulation in these periods can cause growth of the ectopic thyroid gland. ${ }^{4}$ An important percentage of the cases in the study from Korea were diagnosed during puberty and pregnancy, supporting this mechanism. ${ }^{2}$ Our case with a sublingual thyroid gland was also diagnosed during puberty after thyroid function tests requested for other reasons were found to be abnormal. However, pressure symptoms of dyspnea, dysphonia, or dysphagia had not developed in our patient.

The thyroid gland is not observed in its normal place in $70-80 \%$ of lingual ectopic thyroid gland cases and thus there is a single thyroid gland that represents the function of the ectopic gland. ${ }^{2}$ We also did not observe a thyroid gland in the thyroid lodge of our patient on thyroid scintigraphy. If surgery is performed in such patients, auto transplantation to the neck muscles can be attempted after the lingual thyroid gland is excised in order to protect the only thyroid tissue that is available. ${ }^{3}$

Hypothyroidism is found in $33 \%$ of ectopic thyroid gland cases. ${ }^{7}$ Subclinical hypothyroidism was present in our patient. Our patient had thyroid function even without treatment but we started thyroid hormone replacement as we thought that the increased TSH could cause sublingual thyroid gland growth and pressure symptoms. Previous studies have reported a slow decrease in the volume of ectopic thyroid tissue with the use of thyroid hormones in patients with high TSH levels. Surgical treatment should be considered when mass-related pressure symptoms or hemorrhage develops or malignancy is suspected. ${ }^{4}$ Thyroid ablation with radioactive iodine can be an alternative treatment choice in cases refusing surgery. ${ }^{3}$

In conclusion, lingual, sublingual and submandibular ectopic thyroid tissue is a rare developmental abnormality of the thyroid gland. These cases can be diagnosed with subclinical hypothyroidism in the pubertal period when the need for thyroid hormones increases, as in our patient. Although the patients who are diagnosed with ectopic thyroid tissue are euthyroid, they should be followed-up for changes that may develop in thyroid functions and for the malignant transformation risk.

\section{Acknowledgements}

None.

\section{Conflict of interest}

The author dcelares no conflict of interest.

\section{References}

1. Siguaa Rodriguez EA, Goulart DR, Asprino L, et al. Conservative management for lingual tyhroid ectopic. Case Rep Otolaryngol. 2015;2015:267207.

2. Yoon JS, Won $\mathrm{KC}$, Cho IH, et al. Clinical characteristics of ectopic thyroid in Korea. Thyroid. 2007;17(11):1117-1121.

3. Kumar SS, Kumar DM, Thirunavukuarasu R. Lingual thyroidconservative management or surgery. a case report. Indian J Surg. 2013;75(Suppl 1):118-119.

4. Adelchi C, Mara P, Melissa L, et al. Ectopic thyroid tissue in the head and neck: a case series. BMC Res Notes. 2014;7:790.

5. Bukachevsky RP, Casler JD, Oliver J, et al. Squamous cell carcinoma and lingual thyroid. Ear Nose Throat J. 1991;70(8):505-507.

6. Ulug T, Ulubil SA, Alagol F. Dual ectopic thyroid: report of a case. See comment in PubMed Commons belowJ Laryngol Otol. 2003;117(7):574 576.

7. Di Benedetto. Ectopict thyroid gland in the submandibular region simulating a thyroglossal duct cyst: a case report. J Pediatr Surg. 1997;32(12):1745-1746. 